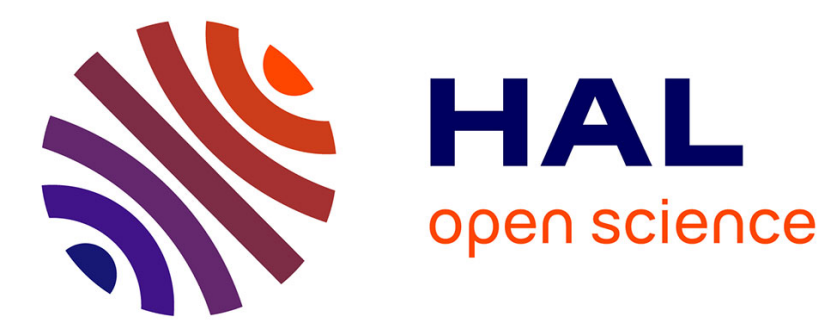

\title{
Neutral sugar side chains of pectins limit interactions with procyanidins
}

\author{
Aude Watrelot, Carine Le Bourvellec-Samour, Anne Imberty, Catherine
}

M.G.C. Renard

\section{- To cite this version:}

Aude Watrelot, Carine Le Bourvellec-Samour, Anne Imberty, Catherine M.G.C. Renard. Neutral sugar side chains of pectins limit interactions with procyanidins. Carbohydrate Polymers, 2014, 99, pp.527-536. 10.1016/j.carbpol.2013.08.094 . hal-02640610

\section{HAL Id: hal-02640610 https://hal.inrae.fr/hal-02640610}

Submitted on 28 May 2020

HAL is a multi-disciplinary open access archive for the deposit and dissemination of scientific research documents, whether they are published or not. The documents may come from teaching and research institutions in France or abroad, or from public or private research centers.
L'archive ouverte pluridisciplinaire HAL, est destinée au dépôt et à la diffusion de documents scientifiques de niveau recherche, publiés ou non, émanant des établissements d'enseignement et de recherche français ou étrangers, des laboratoires publics ou privés. 


\title{
Neutral sugar side chains of pectins limit interactions with procyanidins
}

\author{
Aude A. Watrelot ${ }^{\mathrm{a}, \mathrm{b}, *}$, Carine Le Bourvellec ${ }^{\mathrm{a}, \mathrm{b}}$, Anne Imberty ${ }^{\mathrm{c}}$, Catherine M.G.C. Renard ${ }^{\mathrm{a}, \mathrm{b}}$ \\ a INRA, UMR408 Sécurité et Qualité des Produits d'Origine Végétale, F-84000 Avignon, France \\ ${ }^{\mathrm{b}}$ Université d'Avignon et des Pays de Vaucluse, UMR408 Sécurité et Qualité des Produits d'Origine Végétale, F-84000 Avignon, France

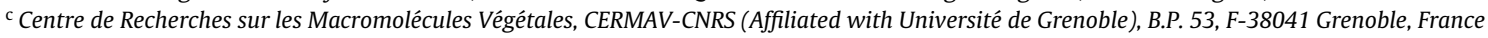

Keywords:

\section{Polyphenol}

Condensed tannins

Polysaccharide

Rhamnogalacturonan

Association

ITC

\author{
A B S T R A C T
}

Interactions between seven hairy regions of pectins, rhamnogalacturonans II and arabinogalactan-proteins and procyanidins with different average degrees of polymerization, low (DP9) and high (DP30), were investigated by isothermal titration calorimetry and absorption analysis to study the impact of neutral sugar side chains of pectins on these associations. Associations between pectic fractions and procyanidins involved hydrophobic interactions and hydrogen bonds. No difference in association constants between various hairy regions and procyanidins DP9 was found. Nevertheless, arabinan chains showed lower association constants, and hairy regions of pectins with only monomeric side chains showed higher association with procyanidin DP30. Only very low affinities were obtained with rhamnogalacturonans II and arabinogalactan-proteins. Aggregation could be observed only with the procyanidins of DP30 and the protein-rich arabinogalactan-protein. Associations were obtained at both degrees of polymerization of the procyanidins, but differed depending on neutral sugar composition and the structure of pectic fractions.

\section{Introduction}

Pectins are complex polysaccharides of plant cell walls, present mostly in the middle lamella and primary wall. They comprise smooth and hairy regions. The "smooth regions", also known as homogalacturonans (HGs), consist of a long chain of $(1 \rightarrow 4)$ linked $\alpha$-D-galacturonic acid (GalpA) with various degrees of methylation and/or acetylation. The hairy regions, named rhamnogalacturonans (RGs), are of two types (I and II) (Caffall \& Mohnen, 2009; De Vries, Rombouts, Voragen, \& Pilnik 1982; Thomas, McNeil, Darvill, \& Albersheim, 1987). Rhamnogalacturonans I are formed by the repeating unit $\rightarrow 4)-\alpha-D-G a l p A-(1 \rightarrow 2)-\alpha-L-R h a p-(1 \rightarrow)$, the rhamnose residues of the RG fractions being decorated by long side-chains composed mostly of galactose and arabinose (Ridley, O’Neill, \& Mohnen, 2001; Voragen, Coenen, Verhoef, \& Schols, 2009). RG I presents this strictly alternating RG backbone (De Vries et al., 1982; Renard, Crépeau, \& Thibault, 1995; Schols, Posthumus, \& Voragen, 1990), while the misleadingly named RG II possesses a backbone of $(1 \rightarrow 4)$ linked $\alpha-D-G a l p A$ as

\footnotetext{
* Corresponding author at: INRA, UMR408 Sécurité et Qualité des Produits d’Origine Végétale, Domaine Saint-Paul, Site Agroparc, 84914 Avignon Cedex 9, France. Tel.: +33043272 25 37; fax: +330432722492.

E-mail addresses: watrelotaude@yahoo.fr, aude.watrelot@avignon.inra.fr (A.A. Watrelot), carine.lebourvellec@avignon.inra.fr (C. Le Bourvellec).
}

homogalacturonans with side chains containing rhamnose and a variety of rare monosaccharides (Pérez, Rodríguez-Carvajal, \& Doco, 2003). Arabinogalactan-proteins (AGPs) are often associated with pectins because both molecules contain a similar structural motif of type II galactans, i.e. $(1 \rightarrow 3)$ and $(1 \rightarrow 6)$ linked galactans ramified with arabinan oligomers (Voragen et al., 2009). However, in AGPs the arabinogalactan domains are connected via a specific hydroxyproline-rich protein (Clarke, Anderson, \& Stone, 1979).

Procyanidins are flavonoids, major polyphenols found in vacuoles of fruits and vegetables. They are a subclass of proanthocyanidins derived from the oligomerization of flavan-3-ols units and form the condensed tannins. They are characterized by their constitutive units, their interflavanic linkages and their degree of polymerization (Hemingway \& Karchesy, 1989; Quideau, Deffieux, Douat-Casassus, \& Pouységu, 2011). Specifically, apple procyanidins are characterized by the predominance of $(-)$-epicatechin and of C4-C8 interflavanic linkages (Guyot, Marnet, Laraba, Sanoner, \& Drilleau, 1998; Sanoner, Guyot, Marnet, Molle, \& Drilleau, 1999; Wojdyło, Oszmianski, \& Laskowski, 2008). They can be oligomers or polymers and in cider apples, their number-average degree of polymerization range between $\overline{\mathrm{DP}} n$ 4.5-50 for varieties Jeanne Renard and Avrolles respectively (Sanoner et al., 1999). They have been reported to exhibit several health effects as antioxidants and anticarcinogens, and to protect against cardiovascular diseases.

Fruit and vegetable processing ruptures cells. This disruption leads to association between constituents of cell walls and vacuoles, 
Version définitive du manuscrit publiée dans / Final version of the manuscript published in :

Carbohydrate Polymers (2014), Vol. 99, p. 527-536, DOI: 10.1016/j.carbpol.2013.08.094

Journal homepage: www.elsevier.com/locate/carbpol

with a prominent role of pectins and procyanidins (Le Bourvellec, Bouchet, \& Renard, 2005). The bioavailability of polyphenols is dependent on their structure and their association with other compounds such as sugars (Parada \& Aguilera, 2007). Procyanidins associated with dietary fiber are not bioaccessible in the upper part of the human intestine, and travel to the colon, where they become fermentable substrates for bacterial microflora (Cheynier, Sarni-Manchado, \& Quideau, 2012; Palafox-Carlos, Ayala-Zavala, \& González-Aguilar, 2011; Saura-Calixto et al., 2010), producing metabolites that are both absorbable and bioactive (Williamson \& Clifford, 2010). In vitro, the interaction between procyanidins and dietary fiber reduces the polysaccharide fermentation and increases the production of procyanidin colonic metabolites (Aura et al., 2012; Saura-Calixto et al., 2010). To understand the health effect of polyphenols after binding to polysaccharides such as pectins, earlier work dealt with mechanisms of interactions between these two macromolecules. In our previous work (Watrelot, Le Bourvellec, Imberty, \& Renard 2013), interactions between procyanidins and pectins were analyzed, and the impact of the degree of methylation of smooth regions and of the degree of polymerization of procyanidins could be demonstrated. However, the role of the hairy regions of pectins has not been determined. The aim of this study was to quantify the binding of a specific class of proanthocyanidins, the procyanidins, to hairy regions of pectins. Isothermal titration calorimetry and a spectrophotometric method were used to probe thermodynamic parameters and aggregation phenomena in interactions between hairy region fractions and procyanidins with different average degrees of polymerization: low (DP9) and high (DP30).

\section{Materials and methods}

\subsection{Chemicals}

Methanol, acetonitrile, and acetone of chromatographic quality were from Biosolve (Distribio, Evry, France). Hexane (Merck, Darmstadt, Germany) was of analytical quality. Ethanol and acetone were from Fisher Scientific (Strasbourg, France).

Silver nitrate was from Merck (Darmstadt, Germany). Sodium borohydride $\left(\mathrm{NaBH}_{4}\right), \mathrm{N}$-methylimidazole, acetic anhydride, toluene- $\alpha$-thiol and pectin from apple were from Sigma-Aldrich (Deisenhofen, Germany). Chlorogenic acid, (+)-catechin, and (-)-epicatechin were from Sigma-Aldrich. 4-Coumaric acid was from Extrasynthèse (Lyon, France). Phloridzin and sugar standards were from Fluka (Buchs, Switzerland). Methanol-d3 was from Acros Organics (Geel, Belgium). Enzymatic cocktail Endozym polifruit liq $^{+}$was from Spindal groupe AEB (Gretz-Armainvilliers, France). Modified hairy regions (MHR1) from apple were kindly supplied and characterized by Dr. M. C. Ralet (INRA-UR1268 Biopolymères Interactions Assemblages, Nantes, France). Modified hairy regions MHR2, MHR3 and MHR4 from pear, onion and soybean (SSPS) respectively were kindly supplied by Dr. Henk Schols (WU Agrotechnology \& Food Sciences, Wageningen, Netherlands). Rhamnogalacturonans of type II monomer and dimer (mRG-II and dRG-II) and arabinogalactan-protein (AGP0 and AGP4) were kindly supplied by Dr. Claire Dufour (INRA-UMR408 Sécurité et Qualité des Produits d'Origine Végétale, Avignon, France).

\subsection{Plant material}

Apple fruits (Malus domestica Borkh.) of the Avrolles and Marie Ménard varieties were harvested at commercial maturity during the 2000 season in the experimental orchard of the Center Technique des Productions Cidricoles (CTPC, Sées, France). Fruits were mechanically peeled and cored as previously described by Guyot,
Doco, Souquet, Moutounet, and Drilleau (1997) and cortex tissues were freeze-dried. Apple pomace was from Val de Vire Bioactives (Condé-sur-Vire, France). Fibrex 615 (Sugar beet pulp) was from Nordic Sugar (Copenhagen, Denmark).

\subsection{Procyanidin extraction and purification}

Procyanidins were extracted from "Marie Ménard" and "Avrolles" freeze-dried pulps by successive solvent extractions and purified as described by Watrelot et al. (2013). The purified procyanidin fractions were designated DP9 (from "Marie Ménard") and DP30 (from “Avrolles"). In the two fractions, (-)-epicatechin was the predominant constitutive unit, accounting for more than $95 \%$ and $88 \%$ in DP30 and DP9 respectively. For details, see Watrelot et al. (2013).

\subsection{Rhamnogalacturonan preparation}

Rhamnogalacturonans were prepared as described by Renard and Jarvis (1999) using $15 \mathrm{~g} / \mathrm{L}$ of apple pectins saponified at $4{ }^{\circ} \mathrm{C}, \mathrm{pH}>12$ and left overnight. The solution was then brought to $\mathrm{pH} 6$ and precipitated with three volumes of an ethanol/water/hydrochloric acid mixture (96:3:1, v/v/v) with stirring at $4{ }^{\circ} \mathrm{C}$ and left overnight. This suspension was filtered on a G0 sintered glass filter. After filtration the pectic acid precipitate was washed thoroughly with an ethanol/water mixture (70:30, $\mathrm{v} / \mathrm{v}$ ) until all remaining chloride ions were eliminated (as verified by silver nitrate precipitation). The resulting powder was dried by solvent exchange (ethanol $96 \%$ and acetone), followed by drying at $40^{\circ} \mathrm{C}$ in an oven overnight. The pectic acid was dissolved $(6 \mathrm{~g} / \mathrm{L})$ and hydrolyzed with hydrochloric acid $(0.25 \mathrm{~N})$ for $72 \mathrm{~h}$ at $80^{\circ} \mathrm{C}$ (Thibault, Renard, Axelos, Roger, \& Crepeau, 1993). The supernatant was concentrated on a rotary evaporator before dialyzing against $0.1 \mathrm{M} \mathrm{NaCl}$ followed by water to eliminate monomers and neutral oligomers (galactose and arabinose). The rhamnogalacturonan oligomers (RG) were finally freeze-dried.

Apple hairy regions were obtained by a modified alkaline peroxide treatment as described by Renard, Lahaye, Mutter, Voragen, \& Thibault (1997). Apple pomace was suspended overnight at room temperature with stirring at $50 \mathrm{~g} / \mathrm{L}$ in water, and $\mathrm{pH}$ was stabilized at $>13$. Polyphenols were then eliminated by adding $200 \mathrm{~mL}$ of hydrogen peroxide (30\%). The medium was left to react with stirring for $2 \mathrm{~h}$. The $\mathrm{pH}$ was adjusted to 5 with acetic acid, and enzymatic cocktail Endozym polifruit liq ${ }^{+}(1 \mathrm{~mL})$ was added and left to act overnight with stirring at room temperature. The suspension was filtered on a nylon membrane ( $250 \mu \mathrm{m}$ pore size) under vacuum. The filtrate was dialyzed against $0.1 \mathrm{M} \mathrm{NaCl}$, and then water at $4{ }^{\circ} \mathrm{C}$. Finally, the filtrate was freeze-dried to give the apple hairy region fraction (AHR).

Acid-treated hairy regions (HR-H) were obtained from sugar beet pulp as described by Ralet, Tranquet, Poulain, Moïse, and Guillon (2010).

Modified hairy regions (MHR1) from apple were prepared by the method of Schols et al. (1990) and were a kind gift from Dr. M.C. Ralet. Modified hairy regions (MHR2 and MHR3) from pear and onion were prepared by the method of Schols and Voragen (1994). MHR4 from soybean was prepared by Coenen (2007). MHR2, MH3 and MHR4 were a kind gift from Dr. Henk Schols. All MHRs resulting from drastic enzymic hydrolysis of plant cell walls were isolated as high molar mass polymers with a rhamnogalacturonan backbone. However, the structure of the side chain depends on the botanical origin (Table 1). MHR1 from apple was mostly composed of $\beta$ $(1 \rightarrow 4)$ linked galactans and arabinans (Renard, Voragen, Thibault, \& Pilnik, 1991; Schols \& Voragen, 1994). They were characterized by a high xylose content with a molar ratio Xyl: GalA of 0.4 , which corresponds to xylogalacturonan chains (Schols, Bakx, Schipper, and 
Version définitive du manuscrit publiée dans / Final version of the manuscript published in :

Carbohydrate Polymers (2014), Vol. 99, p. 527-536, DOI: 10.101.6/j.carbpol.2013.08.094

Journal homepage: www.elsevier.com/locate/carbpol

Table 1

Composition (mg/g dry matter) and partition coefficient of the different rhamnogalacturonan subfractions.

\begin{tabular}{|c|c|c|c|c|c|c|c|c|c|c|}
\hline Samples (mg/g) & $K_{a v}$ & Rha & Fuc & Ara & Xyl & Man & Gal & Glc & GalA & Characteristic structure \\
\hline RG & 0.26 & 49 & 3 & 45 & 15 & 10 & 236 & 128 & 458 & \\
\hline AHR & 0.28 & 23 & 2 & 251 & 16 & - & 30 & 19 & 167 & Arabinan \\
\hline HR-H & 0.13 & 143 & - & 25 & - & - & 199 & - & 437 & RG with monomeric galactans \\
\hline Pooled SD & - & 1.7 & 0.1 & 9.6 & 0.7 & 0.9 & 9.5 & 5.7 & 4.5 & \\
\hline a MHR1 & -0.06 & 89 & 9 & 83 & 113 & - & 134 & - & 385 & Arabinan Type I galactan Xylogalacturonan \\
\hline a MHR2 & -0.03 & 79 & - & 240 & 42 & - & 101 & - & 209 & Arabinan Type II galactan \\
\hline a MHR3 & 0.01 & 132 & - & 40 & 17 & 7 & 208 & - & 283 & Type I galactan \\
\hline bMHR4 & nd & 41 & 33 & 188 & 52 & - & 351 & 27 & 165 & Galactan Xylogalacturonan \\
\hline c AGP0 & 0.08 & 11 & 1 & 358 & 2 & 18 & 583 & 16 & 28 & Type II Arabinogalactan \\
\hline c AGP4 & 0.02 & 93 & 2 & 250 & 18 & 23 & 354 & 3 & 180 & \\
\hline
\end{tabular}

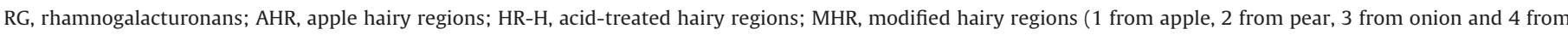

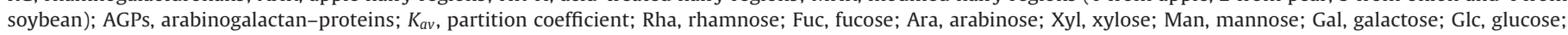
GalA, galacturonic acid. Pooled SD: pooled standard deviation, $n=11$. a: Schols and Voragen (1994); b: Coenen (2007); c: Pellerin et al. (1995).

Voragen, 1995). MHR2 from pear was rich in arabinose present as $(1 \rightarrow 5)$-linked chains (with proportion of $71 \%$ ). Its galactans were predominantly highly ramified $\beta-(1 \rightarrow 3)$ and $\beta-(1 \rightarrow 6)$ type II galactan and galactose residues were terminally linked (with proportion of 36\%) (Schols \& Voragen, 1994). MHR3 from onion was rich in galactose with high proportion of terminal galactose residues (58\%) and in $\beta-(1 \rightarrow 4)$ linked type I galactan(19\%) (Schols \& Voragen, 1994), as was MHR4 from soybean with the additionnal presence of $\beta$-D-Xyl side chains substituted to $(1,4)$-linked galacturonic acid, i.e. also xylogalacturonans (Coenen, Bakx, Verhoef, Schols, \& Voragen, 2007; Nakamura, Furuta, Maeda, Nagamatsu, \& Yoshimoto, 2001).

Polysaccharides isolated from red wine were kindly donated by Dr. C. Dufour (INRA-UMR408 Sécurité et Qualité des Produits d'Origine Végétale, Avignon, France). Rhamnogalacturonans, RGIIs, were purified as described in Pellerin et al. (1996). Fractions mRG-II and dRG-II were predominantly monomeric (90\% pure) and dimeric (87\% pure). Monomer and dimer (mRG-II and dRG-II) were rich in arabinose and composed of rare neutral sugars. The dimer was distinguished by the presence of boron.

Type II arabinogalactan-protein fractions, AGP0 and AGP4, were isolated by anion exchange chromatography according to Pellerin, Vidal, Williams, and Brillouet (1995). Fractions were similar in terms of neutral sugar composition except for arabinose and galactose with higher content in AGP0 (35.2\% and 57.3\%, respectively) than AGP4 (27.1\% and 38.3\%, respectively), while uronic acid content was higher in AGP4 than AGP0. Also, non-reducing arabinose and rhamnose were observed in both AGPs, but rhamnose was 2,4-linked in AGP4. Galactose was 3,6-linked more in AGP4, but 3,4,6-linked more in AGP0 (Pellerin et al., 1995).

\subsection{Phase diagram}

To identify aggregate formation during pectin-tannin interactions, a spectrophotometric method was used at $25^{\circ} \mathrm{C}$. Systematic variation of concentrations and relative amounts was carried out on a 96-well "microplate". This was done by varying the concentrations of procyanidins $(0,0.015,0.03,0.06,0.117,0.23,0.47$, $0.94,1.875,3.75,7.5,15 \mathrm{mmol} / \mathrm{L}(-)$-epicatechin equivalent) along the rows, and varying the concentrations of hairy regions $(0$, $0.12,0.23,0.47,0.94,1.875,3.75,7.5 \mathrm{mmol} /$ Lgalacturonic acid equivalent) along the columns. Solutions were prepared in citrate/phosphate buffer at $\mathrm{pH} 3.8$ and ionic strength $0.1 \mathrm{~mol} / \mathrm{L}$. Equal amounts $(50 \mu \mathrm{L})$ of procyanidin and hairy region fraction solutions were mixed before each spectrum measurement for $20 \mathrm{~s}$. Absorbance spectra $(200-650 \mathrm{~nm})$ were recorded, and absorbance at $650 \mathrm{~nm}$ was analyzed for each solution using a SAFAS flx-Xenius XM spectrofluorimeter (SAFAS, Monaco). Control spectra were obtained using wells containing hairy regions alone in buffer and procyanidins alone in buffer. After spectra recording, microplates were centrifuged for $10 \mathrm{~min}$ at
$2100 \times g$, and supernatants of control wells (hairy regions at $7.5 \mathrm{mmol} / \mathrm{L}$ in buffer (S1A) and procyanidins at $15 \mathrm{mmol} / \mathrm{L}$ in buffer (S1B)) and supernatants of wells containing procyanidins at a concentration of $15 \mathrm{mmol} / \mathrm{L}$ with hairy regions at a concentration of $7.5 \mathrm{mmol} / \mathrm{L}$ (S2) were analyzed by high pressure size exclusion chromatography (HPSEC) and high-performance liquid chromatography-diode array detection (HPLC-DAD) to define changes in partition coefficient $\left(\Delta K_{\mathrm{av}}=\mathrm{S} 2-\mathrm{S} 1 \mathrm{~A}\right)$ of hairy region fractions and in average degree of polymerization of flavan-3-ols $(\Delta \mathrm{DP} n=\mathrm{S} 2-\mathrm{S} 1 \mathrm{~B})$.

\subsection{Isothermal titration microcalorimetry}

To measure enthalpy changes associated with hairy regiontannin interactions at $25^{\circ} \mathrm{C}$, a VP-ITC microcalorimeter (Microcal ${ }^{\circledR}$, GE Healthcare, Northampton, MA, USA) was used. To allow comparison between the different pectic substrates, and given the polydispersity in molecular weight for both pectic fractions and procyanidins, all concentrations are expressed relative to the main monomers, i.e. galacturonic acid for pectins and (-)-epicatechin for procyanidins. Procyanidins and hairy region fractions were dissolved in the same citrate/phosphate buffer $\mathrm{pH} 3.8$, ionic strength $0.1 \mathrm{~mol} / \mathrm{L}$, and filtered on $0.45 \mu \mathrm{m}$ membrane. All the solutions were degassed before measurements. The reference cell was filled with water. To obtain a hyperbolic curve as recommended for low affinity systems (Turnbull \& Daranas, 2003), different concentrations of compounds were tested. The pectic fraction solution was placed in the $1.448 \mathrm{~mL}$ sample cell of the calorimeter, and the procyanidin solution was loaded into the injection syringe and titrated into the sample cell by 30 injections of $10 \mu \mathrm{L}$ aliquots. The duration of each injection was $20 \mathrm{~s}$, with a separating delay of $5 \mathrm{~min}$. The contents of the sample cell were stirred throughout the experiment at $307 \mathrm{rpm}$ to ensure mixing.

Raw data obtained as a plot of heat flow (microcalories per second) against time (minutes) were then integrated peak-bypeak and normalized to obtain a plot of observed enthalpy change per mole of injectant $\left(\Delta H, \mathrm{~kJ} \mathrm{~mol}^{-1}\right)$ against the molar ratio ((-)epicatechin/galacturonic acid). Peak integration was performed using Microcal Origin 7.0 (Microcal Software, GE Healthcare). Control experiments included the titration of procyanidin fractions into buffer, and were subtracted from titration experiments. The experimental data were fitted to a theoretical titration curve using Microcal Origin 7.0, with $\Delta H$ (enthalpy change), $K_{\mathrm{a}}$ (association constant), and $n$ (number of binding sites per molecule) as adjustable parameters, from the relationship

$Q_{i}=\frac{n P_{t} \Delta H V_{0}}{2}\left[1+\frac{A_{t}}{n P_{t}}+\frac{1}{n K a P_{t}}-\sqrt{\left(1+\frac{A_{t}}{n P_{t}}+\frac{1}{n K a P_{t}}\right)^{2}-4 \frac{A_{t}}{n P_{t}}}\right]$ 
Version définitive du manuscrit publiée dans / Final version of the manuscript published in :

Carbohydrate Polymers (2014), Vol. 99, p. 527-536, DOI: 10.1016/j.carbpol.2013.08.094

Journal homepage: www.elsevier.com/locate/carbpol

where $P_{t}$ is the total galacturonic acid concentration, $A_{\mathrm{t}}$ is the total concentration of the ligand, $V_{0}$ is the volume of the cell, and $Q_{i}$ is the total heat released for injection $i$.

The other thermodynamic parameters $(\Delta G$ and $\Delta S$ ) were calculated from the van't Hoff equation.

$\Delta G=-R \operatorname{TIn} K_{a}=\Delta H-T \Delta S$

where $\Delta G$ is free enthalpy, $K_{a}$ is the association constant, $\Delta H$ is the enthalpy and $\Delta S$ is the entropy of interaction.

\subsection{Analysis methods}

Polyphenols were measured by high-performance liquid chromatography (HPLC)/diode array detection (DAD) after thioacidolysis as described by Guyot, Marnet, and Drilleau (2001) and Le Bourvellec et al. (2011). Analyses were performed using an ultra fast liquid chromatography Shimadzu Prominence system (Kyoto, Japan) comprising two LC-20AD pumps, UFLC Prominence liquid chromatograph, a DGU-20A5 Prominence degasser, a SIL-20ACHT Prominence autosampler, a CTO-20AC Prominence column oven, a SPD-M20A Prominence diode array detector, and a CBM-20A Prominence communication bus module, and was controlled by LC Solution software (Shimadzu, Kyoto, Japan). Separations were achieved in the conditions of Le Bourvellec et al. (2011). The average degree of polymerization (DPn) of procyanidins was measured by calculating the molar ratio of all the flavan-3-ol units (thioether adducts plus terminal units) to (-)-epicatechin and (+)-catechin corresponding to terminal units. Neutral sugars, galacturonic acid and methanol were analyzed as described by Renard and Ginies (2009).

The molecular weight distribution of polysaccharides was determined using a high pressure size exclusion chromatography (HPSEC) system comprising a Jasco LC-NET II/ADC interface, a Jasco PU-2080 plus intelligent HPLC pump, a Jasco RI-2031 plus intelligent RI detector, and a degasser, and was controlled by ChromNav solftware (Jasco, Tokyo, Japan). Separations were achieved using two columns in series: a $8.0 \mathrm{~mm} \times 300 \mathrm{~mm}$ i.d. $\mathrm{OH}-$ pack SB-802 HQ column (Showa Denko Europe, Munich, Germany) and a $300 \times 7.8 \mathrm{~mm}$ i.d. TSK-Gel PWXL column (Tosohaas, Stuttgart, Germany) at $35^{\circ} \mathrm{C}$ and a $40 \times 6.0 \mathrm{~mm}$ i.d. guard column TSK-Gel PWXL (Tosohaas, Stuttgart, Germany). Solutions $(20 \mu \mathrm{L})$ of the extracts $(10 \mathrm{~g} / \mathrm{L})$ were injected and eluted with $0.4 \mathrm{~mol} / \mathrm{Lsodium}$ acetate buffer pH 3.5 at $0.8 \mathrm{~mL} / \mathrm{min}$. Dextrans T500, T70, T40 and T10 (Pharmacia BioProcess Technology, Uppsala, Sweden) and glucose (Sigma-Aldrich, Deisenhofen, Germany) were used to calibrate the column system.

\subsection{Statistical analysis}

Results are presented as mean values, and the reproducibility of the results is expressed as pooled standard deviation. Pooled standard deviations were calculated for each series of replicates using the sum of individual variances weighted by the sum of individual degrees of freedom (Box, Hunter, \& Hunter, 1978).

\section{Results}

\subsection{Composition of the hairy regions}

The characterization of hairy regions is shown in Table 1 . RG contained a high proportion of galacturonic acid, with a molar ratio GalA:Rha > 7, indicating the predominance of homogalacturonans in the backbone. Its main neutral sugars were galactose and glucose. AHR contained a substantial portion of homogalacturonans (GalA:Rha $=6$ ), but unlike $R G$, it also contained a high proportion of arabinan (molar ratio Ara:Rha >10). HR-H was the simplest rhamnogalacturonan fraction, with the lowest neutral sugar content. The molar ratio GalA:Rha of 2.5 is consistent with the rhamnogalacturonic backbone, while the low (Gal+Ara):Rha ratio $(<2)$ corresponds to very short side chains of arabinogalactan (Voragen et al., 2009). MHR1 and MHR4 contained more homogalacturonic backbone (GalA:Rha = 3.6:3.4, respectively) than MHR2 and MHR3 with a molar ratio GalA: Rha of 2.2 and 1.8, respectively.

The partition coefficients of RG and AHR were identical ( $K_{a v}$ of 0.26 and 0.28 respectively with retention times of $17.2 \mathrm{~min}$ and $17.4 \mathrm{~min}$ ), corresponding to small polymers obtained after acid hydrolysis from commercial pectins or after enzymatic reaction from apple pomace. The partition coefficient of $\mathrm{HR}-\mathrm{H}$ fraction was lower ( $K_{a v}$ of 0.13 with a retention time of $16.3 \mathrm{~min}$ ), indicating a higher hydrodynamic volume. Partition coefficients were close between RG-IIs ( $K_{a v}$ of 0.27 for $\mathrm{mRG}$-II and 0.22 for dRG-II) and were in good agreement with calculated molecular weight (Pellerin et al., 1996). Partition coefficients of AGPs were low ( $K_{a v}$ of 0.02 for AGP4) and similar to commercial apple pectins (Watrelot et al., 2013).

\subsection{Interactions with procyanidins of DPn 9}

\subsubsection{Hairy regions}

Thermograms of titration of hairy region fractions $(3.75 \mathrm{mmol} / \mathrm{L}$ galacturonic acid equivalent) by procyanidins DP9 (7.5 $\mathrm{mmol} / \mathrm{L}(-)$ epicatechin equivalent) are shown in Fig. 1.

The blank experiment (injections of procyanidins DP9 in buffer) yielded small endothermic peaks that were subtracted before integration. The thermogram of titration of RG by procyanidins DP9 (Fig. 1a) showed small exothermic peaks for the first injections, and stronger endothermic peaks after saturation. The thermogram of AHR titration by procyanidins DP9 (Fig. 1b) showed strong exothermic peaks $(-8 \mu \mathrm{J} / \mathrm{s})$ with clear titration.

Thermodynamic parameters are shown in Table 2. Stoichiometry (defined as ratio of (-)-epicatechin/galacturonic acid) was fixed at 0.01 for RG (1 molecule of (-)-epicatechin binds with 100 molecules of galacturonic acid) and 0.02 for other fractions (1 molecule of (-)-epicatechin binds with 50 molecules of galacturonic acid) using a one-site model. The association constant $\left(K_{a}=2.53 \times 10^{3} \mathrm{M}^{-1}\right)$ observed for RG and DP9 was of the same order of magnitude as that measured for AHR, HR-H, MHR1 and MHR3 $\left(K_{a}\right.$ from $1955 \mathrm{M}^{-1}$ to $\left.2225 \mathrm{M}^{-1}\right)$. The value of $K_{a}$ was lower for interaction between MHR2 and procyanidins DP9 $\left(K_{a}=872 \mathrm{M}^{-1}\right)$. Analysis of the thermodynamic contributions indicated an enthalpy contribution $\left(\Delta H=-18 \mathrm{~kJ} \mathrm{~mol}^{-1},-16 \mathrm{~kJ} \mathrm{~mol}^{-1}\right.$ and $-26 \mathrm{~kJ} \mathrm{~mol}^{-1}$ for HR-H, MHR2 and MHR3, respectively) related to the exothermic interaction. The entropy term between HR$\mathrm{H}$, MHR2 and procyanidins DP9 was almost null $(-T \Delta S=-0.3$ to $-0.5 \mathrm{~kJ} \mathrm{~mol}^{-1}$, respectively), indicating a weak role of hydrophobic interactions. The analysis of the thermodynamic contributions for MHR3 gave a negative entropy term $\left(-T \Delta S=7 \mathrm{~kJ} \mathrm{~mol}^{-1}\right)$ indicating that the interaction was driven by enthalpy, which may result from hydrogen bond association. A favorable entropy contribution was observed for RG, AHR and MHR1 ( $\left.-T \Delta S \sim-13 \mathrm{~kJ} \mathrm{~mol}^{-1}\right)$, indicating that the interaction was driven mostly by entropy, which may result from hydrophobic interactions (Poncet-Legrand, Gautier, Cheynier, \& Imberty, 2007; Frazier et al., 2010). The titration of MHR from soybean (MHR4) by procyanidins DP9 (data not shown) displayed strong exothermic peaks, but no thermodynamic parameters could be defined.

The absence of differences in affinity between hairy regions and procyanidins DP9 was confirmed by UV-vis absorbance at $650 \mathrm{~nm}$. Fig. 2a and c shows the variation of absorbance at $650 \mathrm{~nm}$ between hairy regions (RG, AHR, HR-H, MHR1, MHR2 and MHR3) and procyanidins DP9 at $15 \mathrm{mmol} / \mathrm{L}(-)$-epicatechin equivalent with the 
Version définitive du manuscrit publiée dans / Final version of the manuscript published in :

Carbohydrate Polymers (2014), Vol. 99, p. 527-536, DOI: 10.1016/j.carbpol.2013.08.094

Journal homepage: www.elsevier.com/locate/carbpol
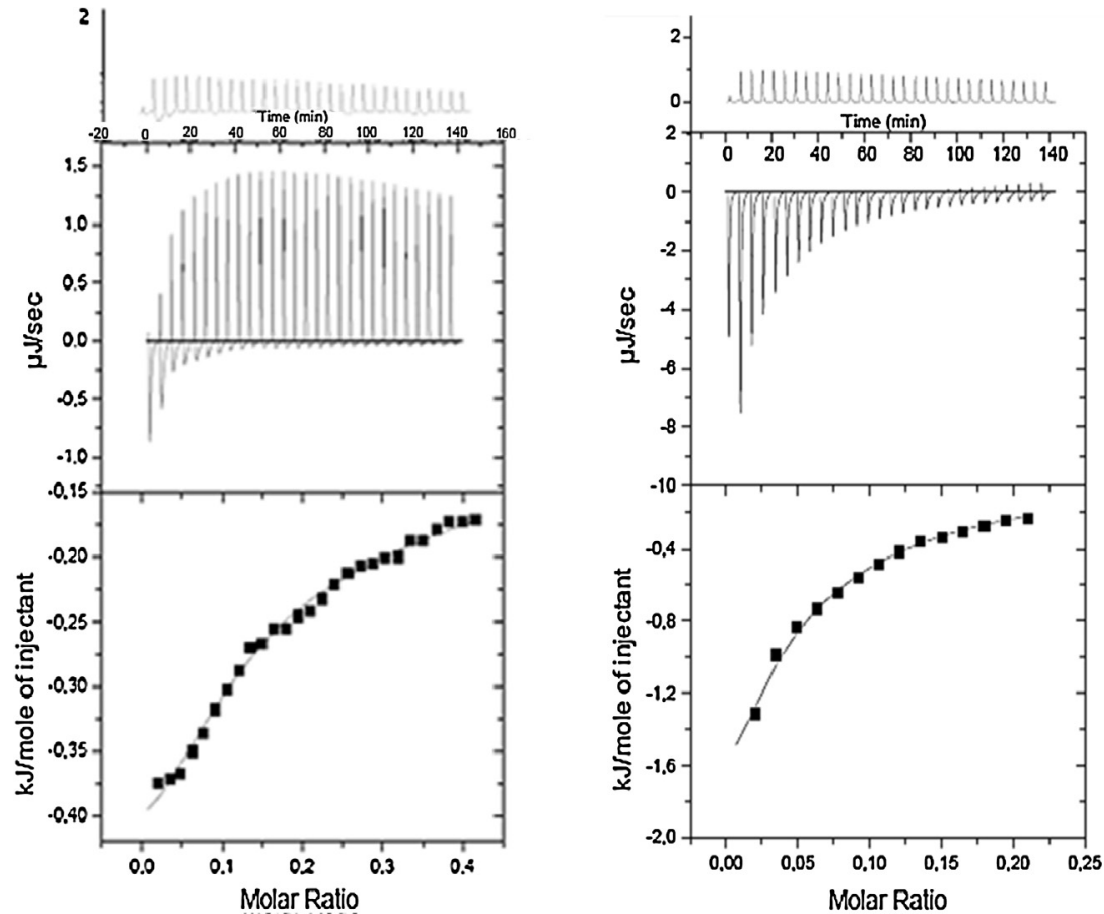

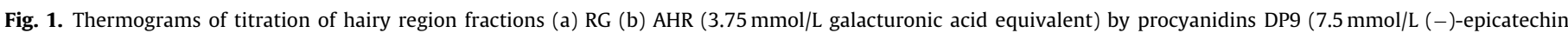

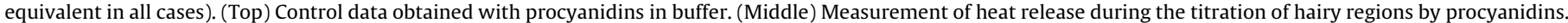

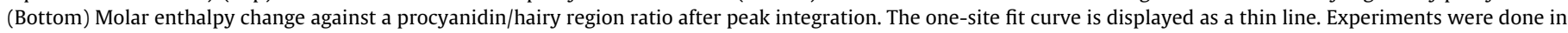
duplicate.

increase of concentrations of hairy regions, standardized here in galacturonic acid equivalent. Absorbance at $650 \mathrm{~nm}$ was chosen as an indicator for the formation of cloud and precipitate, as neither pectins nor procyanidins absorb at this wavelength. Absorbance of all hairy regions with procyanidins DP9 was low (0.04), quite stable and similar between hairy regions. Only the MHR3 fraction showed an increase in absorption up to 0.08 from $1.875 \mathrm{mmol} / \mathrm{L}$ galacturonic acid equivalent. Fig. $2 \mathrm{~b}$ and $\mathrm{d}$ shows the variation in absorbance between hairy regions (RG, AHR, HR-H, MHR1, MHR2 and MHR3) at $7.5 \mathrm{mmol} / \mathrm{L}$ galacturonic acid equivalent and procyanidins DP9 with the increase in concentrations of procyanidins DP9, given in (-)-epicatechin equivalent. Initially, all hairy regions displayed a slight turbidity, which disappeared with addition of a low concentration of procyanidins. With the increase in procyanidin concentrations, absorbance of hairy regions RG, AHR and $\mathrm{HR}-\mathrm{H}$ increased slightly (up to 0.04) and in a similar fashion. Among MHRs fractions (Fig. 2d), MHR3 showed an increase in absorption up to 0.08 from $0.94 \mathrm{mmol} / \mathrm{L}(-)$-epicatechin equivalent, while MHR1 and 2 were stable around 0.01 .

The $\Delta K_{a v}$ correspond to the difference in partition coefficient in HPSEC between the pectic hairy regions (at $7.5 \mathrm{mmol} / \mathrm{L}$ in galacturonic acid equivalent) that had not formed aggregates with procyanidins (at $15 \mathrm{mmol} / \mathrm{L}$ (-)-epicatechin equivalent) (S2) and the initial pectic compounds in buffer (S1A). After centrifugation of hairy regions incubated with procyanidins DP9, values of $\Delta K_{a v}$ obtained were close to nil irrespective of the pectic fractions (Table 2). There was no difference in hydrodynamic volume for hairy regions before and after association with procyanidins DP9.The $\triangle \mathrm{DP} n$ corresponds to the difference in degree of polymerization between procyanidins that had not formed aggregates with

Table 2

Thermodynamic binding parameters of interaction between pectic compounds and procyanidin fractions DP9 and DP30 (30 mmol/L in (-)-epicatechin equivalent).

\begin{tabular}{|c|c|c|c|c|c|c|c|c|c|c|c|}
\hline DP 9 & RG & AHR & HR-H & MHR1 & MHR2 & MHR3 & MHR4 & mRG-II & dRG-II & AGPO & AGP4 \\
\hline$n$ & 0.01 & 0.02 & 0.02 & 0.02 & 0.02 & 0.02 & - & - & - & 0.02 & 0.02 \\
\hline$K_{\mathrm{a}}\left(\mathrm{M}^{-1}\right)$ & 2530 & 1955 & 1850 & 2105 & 872 & 2225 & - & - & - & 44 & 57 \\
\hline$\Delta H\left(\mathrm{~kJ} . \mathrm{mol}^{-1}\right)$ & -6 & -3 & -18 & -5 & -16 & -26 & - & - & - & -67 & -38 \\
\hline$\Delta G\left(\mathrm{~kJ} \cdot \mathrm{mol}^{-1}\right)$ & -19 & -19 & -19 & -19 & -17 & -19 & - & - & - & -9 & -10 \\
\hline$\Delta S\left(\mathrm{~J} \cdot \mathrm{mol}^{-1} \cdot \mathrm{K}^{-1}\right)$ & 45 & 51 & 1 & 47 & 2 & -25 & - & - & - & -193 & -95 \\
\hline$\Delta K_{\mathrm{av}}$ & -0.001 & 0.000 & 0.006 & 0.001 & -0.002 & -0.001 & nd & 0.002 & -0.001 & 0.001 & 0.005 \\
\hline$\Delta \overline{D P} n$ & -1.61 & -1.06 & -1.07 & 0.17 & 0.00 & -0.55 & nd & 0.15 & -0.16 & -0.22 & 0.15 \\
\hline DP 30 & RG & AHR & HR-H & MHR1 & MHR2 & MHR3 & MHR4 & RGII2 & RGII3 & AGPO & AGP4 \\
\hline$n$ & 0.02 & 0.02 & 0.02 & 0.02 & 0.02 & 0.02 & - & 0.02 & 0.02 & 0.02 & 0.02 \\
\hline$K_{\mathrm{a}}\left(\mathrm{M}^{-1}\right)$ & 2620 & 574 & 5390 & 1835 & 875 & 1170 & - & 72 & 62 & 112 & 165 \\
\hline$\Delta H\left(\mathrm{~kJ} \mathrm{~mol}^{-1}\right)$ & -3 & -17 & -4 & -7 & -24 & -41 & - & -16 & -14 & -54 & -31 \\
\hline$\Delta G\left(\mathrm{~kJ} \mathrm{~mol}^{-1}\right)$ & -19 & -16 & -21 & -19 & -17 & -17 & - & -11 & -10 & -12 & -13 \\
\hline$\Delta S\left(\mathrm{~J} \mathrm{~mol}^{-1} \cdot \mathrm{K}^{-1}\right)$ & 56 & -4 & 59 & 38 & -23 & -78 & - & -18 & -12 & -142 & -61 \\
\hline$\Delta K_{\mathrm{av}}$ & 0.004 & 0.004 & 0.015 & 0.011 & 0.004 & -0.006 & nd & 0.000 & -0.004 & 0.009 & 0.011 \\
\hline$\Delta \overline{D P} n$ & -11.82 & -10.17 & -9.49 & -4.89 & -5.01 & -8.44 & nd & 0.28 & 0.27 & -3.62 & 0.53 \\
\hline
\end{tabular}

Average of duplicates for each measurement. Stoichiometry corresponds to the molar ratio value of (-)-epicatechin/galacturonic acid. nd: not defined. 
Version définitive du manuscrit publiée dans / Final version of the manuscript published in :

Carbohydrate Polymers (2014), Vol. 99, p. 527-536, DOI: 10.1016/j.carbpol.2013.08.094

Journal homepage: www.elsevier.com/locate/carbpol
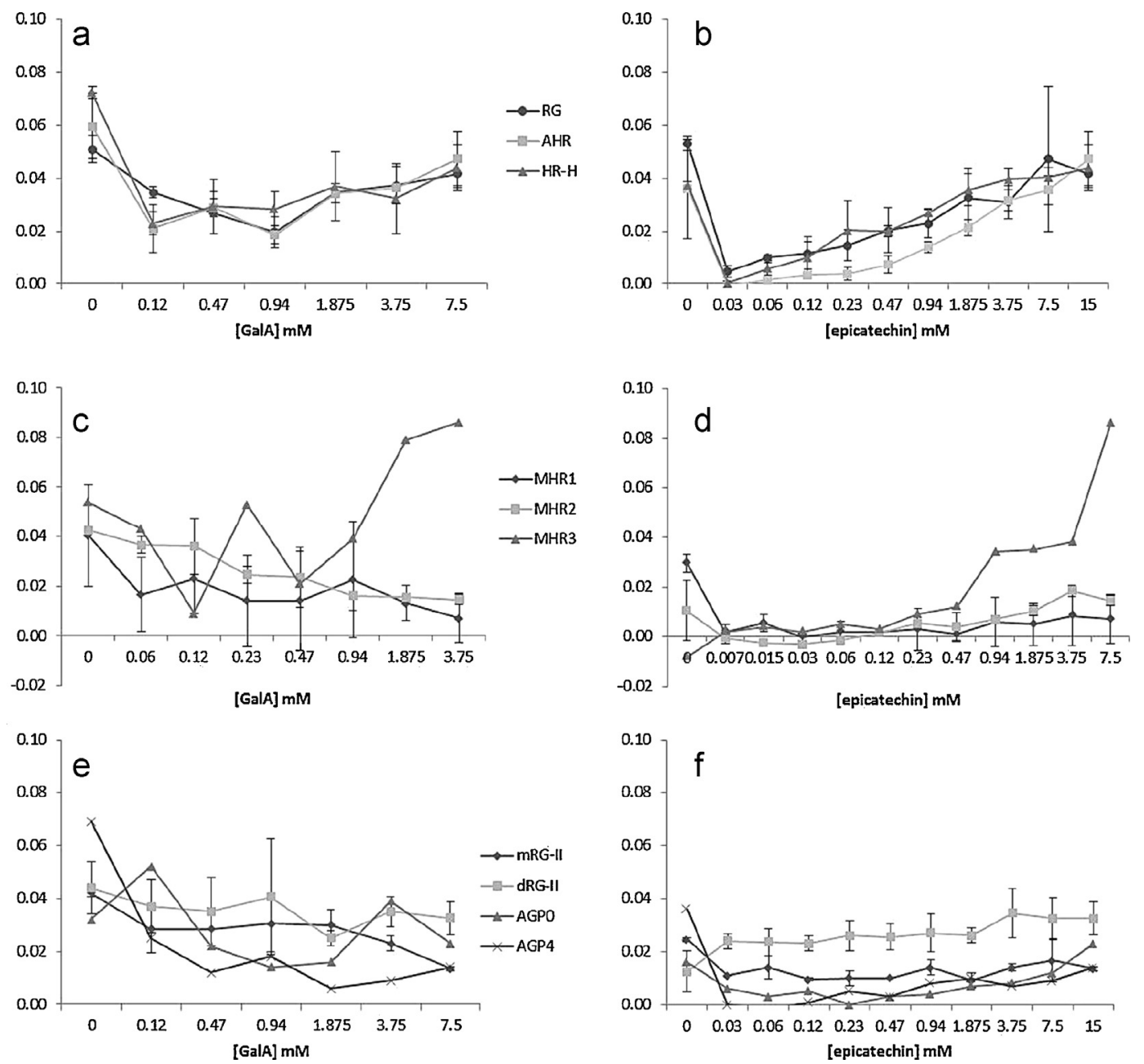

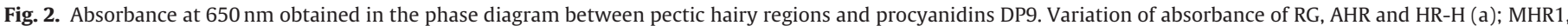

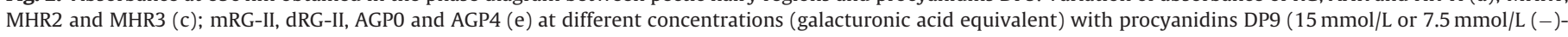

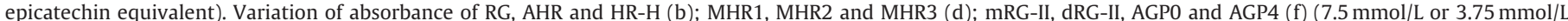
galacturonic acid equivalent) at different concentration of procyanidins DP9 ((-)-epicatechin equivalent).

pectins (S2) and the initial degree of polymerization of procyanidins in buffer (S1B). The $\triangle \mathrm{DPn}$ was -1.61 for RG and -1.06 for AHR and HR-H. The degree of polymerization of free procyanidins was slightly lower than the initial degree of polymerization of procyanidins, i.e. hairy regions RG, AHR and HR-H precipitated preferentially with highly polymerized procyanidins. The value of $\triangle \mathrm{DP} n$ of MHR3 was slightly negative, but there was no difference for MHR2 and MHR1. This means that MHR3, MHR1 and MHR2 were not selective with procyanidins DP9.

\subsubsection{Rhamnogalacturonans II and arabinogalactan-proteins}

During injection of procyanidins in rhamnogalacturonans type II (mRG-II and dRG-II), peaks were endothermic and heat was absorbed. No titration could be observed. Hence no interaction could be detected by ITC between RGIIs and procyanidins DP9.

A thermogram of titration of arabinogalactan-protein by procyanidins DP9 displayed only exothermic peaks (data not shown). Thermodynamic parameters were calculated from raw data after subtraction of blank experiments (procyanidins DP9 in buffer) (Table 2). Stoichiometry was fixed at 0.02 using a one-site model. Association constants obtained for AGP0 and AGP4 were very weak $\left(K_{a}=44 \mathrm{M}^{-1}\right.$ and $57 \mathrm{M}^{-1}$, respectively) and correspond to the limit of detection by isothermal titration calorimetry.

The variation of absorbance at $650 \mathrm{~nm}$ between rhamnogalacturonans II and arabinogalactan-proteins and procyanidins DP9 at
$15 \mathrm{mmol} / \mathrm{L}$ (-)-epicatechin equivalent with the increase in concentrations of rhamnogalacturonans in galacturonic acid equivalent is shown in Fig. 2e. Whatever the pectic fraction, the absorption was stable at around 0.04 . The variation of absorbance between RG-IIs and AGPs at $7.5 \mathrm{mmol} / \mathrm{L}$ galacturonic acid equivalent and procyanidins DP9 with the increase in concentrations of procyanidins DP9 in (-)-epicatechin equivalent (Fig. 2f) was low (0.01) and stable between fractions, but the dimer of RGII (dRG-II) showed absorption at 0.03 .

The $\Delta K_{a v}$ obtained was close to nil for all RGIIs and AGPs. With RGIIs and AGPs, the $\Delta K_{a v}$ and $\Delta \mathrm{DPn}$ were very low or nil: there was no selective precipitation of either the procyanidins or the polysaccharides.

\subsection{Interaction with procyanidins of DPn 30}

\subsubsection{Hairy regions}

ITC measurements were made with $3.75 \mathrm{mmol} / \mathrm{L}$ of pectic compound (galacturonic acid equivalent) and $7.5 \mathrm{mmol} / \mathrm{L}((-)$ epicatechin equivalent) of procyanidins DP30.

Titration of RG, AHR, HR-H and MHR1, MHR2 and MHR3 by procyanidins DP30 showed complex curves characterized by strong exothermic peaks (Fig. 3a and b); to avoid over-fitting, the stoichiometry was fixed at 0.02 for all fractions to allow fit and determination of association parameters. 
Version définitive du manuscrit publiée dans / Final version of the manuscript published in :

Carbohydrate Polymers (2014), Vol. 99, p. 527-536, DOI: 10.1016/j.carbpol.2013.08.094

Journal homepage: www.elsevier.com/locate/carbpol
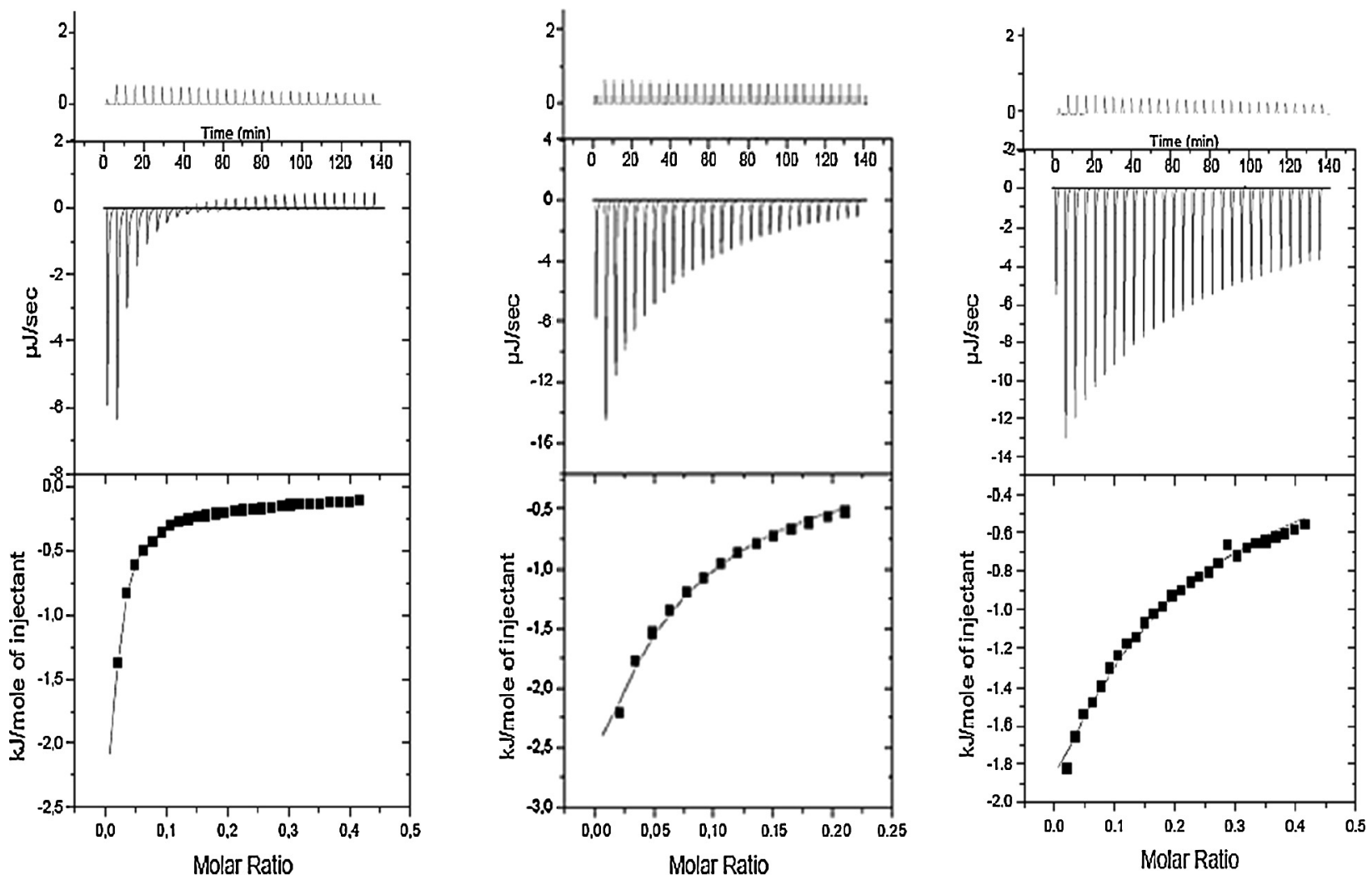

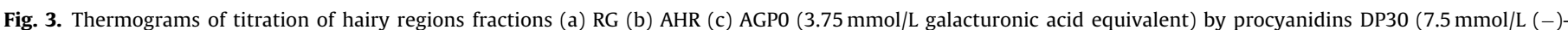

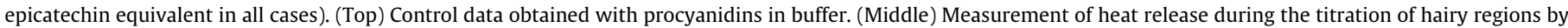

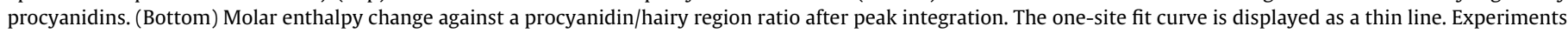
were done in duplicate.

Thermodynamic parameters are presented in Table 2. The association constant $K_{a}$ ranged from $574 \mathrm{M}^{-1}$ to $5390 \mathrm{M}^{-1}$ in the order $\mathrm{AHR}<\mathrm{MHR} 2<\mathrm{MHR} 3<\mathrm{MHR} 1<\mathrm{RG}<\mathrm{HR}-\mathrm{H}$. Concerning the interaction between HR-H, RG and MHR1 and procyanidins DP30, thermodynamic contributions $\left(\Delta H=-4 ;-3\right.$ and $-7 \mathrm{~kJ} \mathrm{~mol}^{-1}$ and $-T \Delta S=-16.1 ;-15.3$ and $-10.4 \mathrm{~kJ} \mathrm{~mol}^{-1}$, respectively) indicated that the interaction was driven mostly by entropy, also indicating the role of hydrophobic interactions (Frazier et al., 2010; PoncetLegrand et al., 2007). However, thermodynamic contributions for the interaction between AHR, MHR2 and MHR3 with procyanidins DP30 showed a very weak entropy $\left(-T \Delta S=1 ; 6\right.$ and $21 \mathrm{~kJ} \mathrm{~mol}^{-1}$, respectively), but a high enthalpy contribution $(\Delta H=-17 ;-24$ and $-41 \mathrm{~kJ} \mathrm{~mol}^{-1}$, respectively), which indicates that the association was mostly driven by enthalpy and also involves hydrogen bonds. The titration of MHR from soybean (MHR4) by procyanidins DP30 displayed very strong exothermic peaks, but no thermodynamic parameters can be defined, because it seemed that binding sites could not be saturated in these conditions.

Absorbance at $650 \mathrm{~nm}$ obtained between hairy regions and procyanidins DP30 at $15 \mathrm{mmol} / \mathrm{L}(-)$-epicatechin equivalent with the variation of concentrations of hairy regions in galacturonic acid equivalent (Fig. 4a) showed an increase in absorbance from $0.12 \mathrm{mM}$ in galacturonic acid equivalent and from 0.04 to 0.14 absorbance $650 \mathrm{~nm}$ for RG and AHR with a very high standard deviation due to the formation of aggregates. The same increase with a high standard deviation was obtained for absorbance at $650 \mathrm{~nm}$ with variation of concentrations of procyanidins DP30 and hairy regions at $7.5 \mathrm{mmol} / \mathrm{L}$ of galacturonic acid (Fig. 4b). For MHRs fractions (Fig. 4c and d), the absorbance was quite stable as a function of galacturonic acid concentrations, but MHR3 showed a slight increase from $0.94 \mathrm{mmol} / \mathrm{L}$ (from 0.04 absorbance) up to 0.09 . It was similar with the increase in (-)-epicatechin concentrations from $0.94 \mathrm{mmol} / \mathrm{L}(0.02)$.

The $\Delta K_{a v}$ corresponds to the difference in partition coefficient in HPSEC between the hairy regions (at $7.5 \mathrm{mmol} / \mathrm{L}$ in galacturonic acid equivalent) that had not formed aggregates with procyanidins (at $15 \mathrm{mmol} / \mathrm{L}(-)$-epicatechin equivalent) (S2) and the initial pectic compounds in buffer (S1A). The $\Delta K_{a v}$ was close to null for all hairy regions. This means there was no selectivity of procyanidins DP30 for hairy regions. The $\triangle \mathrm{DP} n$ corresponds to the difference in degree of polymerization between procyanidins that had not formed aggregates with pectins (S2) and the initial degree of polymerization of procyanidins in buffer (S1B). The value of $\triangle \mathrm{DPn}$ was negative for every hairy region from -4.89 (MHR1) to -11.82 (RG). This means that hairy regions interacted preferentially with highly polymerized procyanidins.

\subsubsection{Rhamnogalacturonans II and arabinogalactan-proteins}

Titration of monomer and dimer of rhamnogalacturonans type II (mRG-II and dRG-II) by procyanidins DP30 displayed weak exothermic peaks (data not shown) resulting in weak association constants $\left(K_{a}=72-62 \mathrm{M}^{-1}\right)$ (Table 2$)$. The isothermal titration calorimetry method may not be the most appropriate one for such low affinity interactions.

During titration of arabinogalactan-proteins AGP0 and AGP4 by procyanidins DP30, strong exothermic peaks were obtained (Fig. 3c), but the association constants were of the same order of magnitude as for rhamnogalacturonans II. Hence only weak associations could be detected by ITC for rhamnogalacturonans II and arabinogalactan-proteins.

The variation of absorbance at $650 \mathrm{~nm}$ of RG-IIs and AGPs with procyanidins DP30 at $15 \mathrm{mmol} / \mathrm{L}$ (-)-epicatechin equivalent 
Version définitive du manuscrit publiée dans / Final version of the manuscript published in :

Carbohydrate Polymers (2014), Vol. 99, p. 527-536, DOI: 10.1016/j.carbpol.2013.08.094

Journal homepage: www.elsevier.com/locate/carbpol
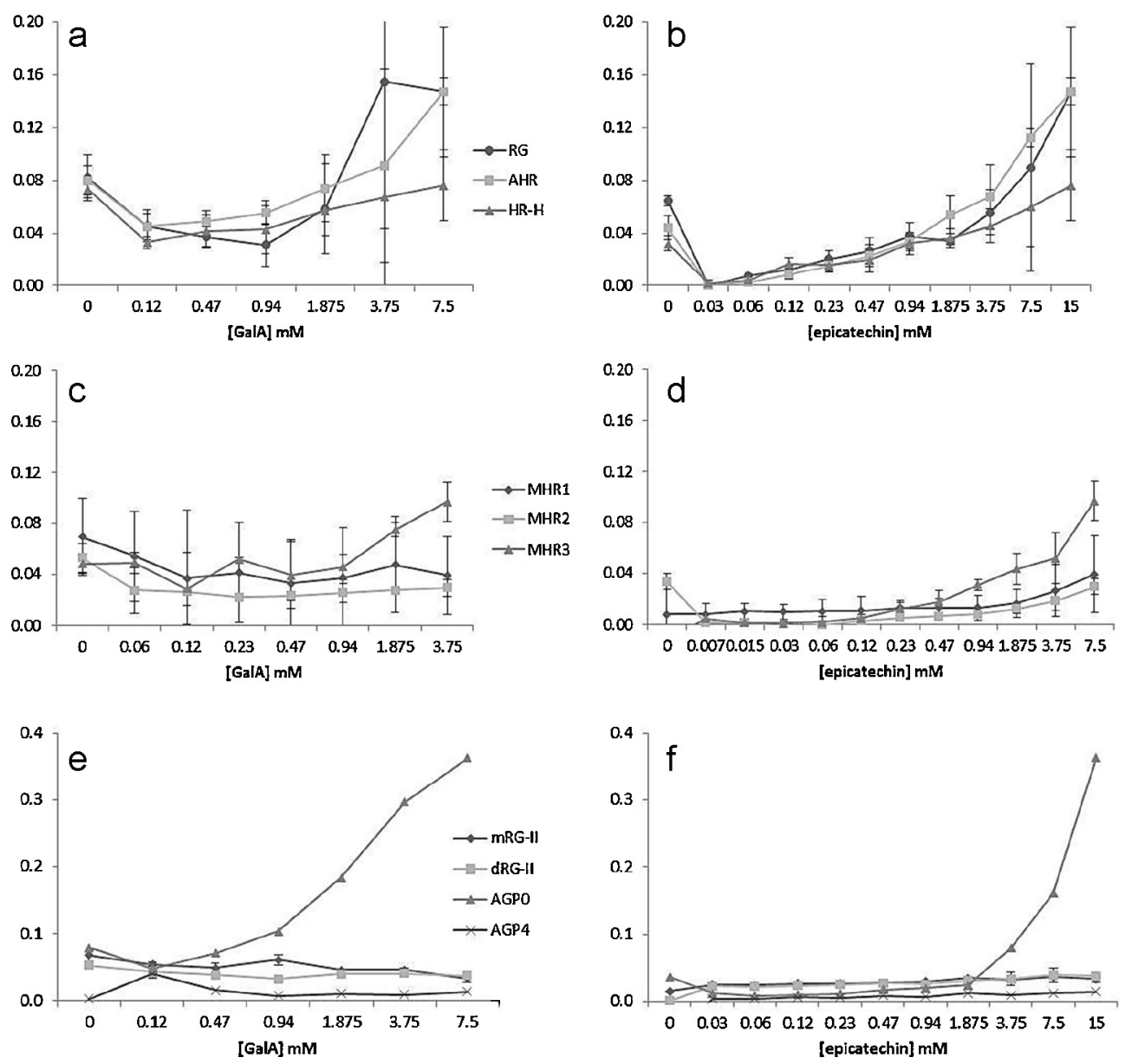

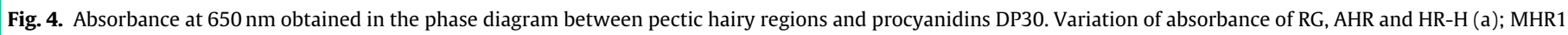

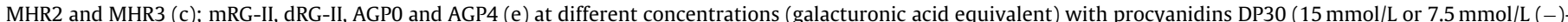

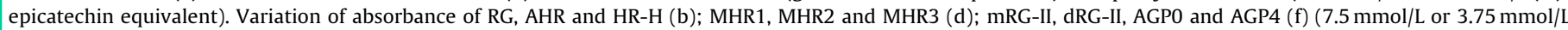
galacturonic acid equivalent) at different concentrations of procyanidins DP30 ((-)-epicatechin equivalent).

(Fig. 4e) showed no variation with the increase in galacturonic acid concentrations for RG-IIs and AGP4, but for AGP0 the absorbance at $650 \mathrm{~nm}$ increased markedly from $0.12 \mathrm{mmol} / \mathrm{L}$ galacturonic acid equivalent, and at a constant $7.5 \mathrm{mmol} / \mathrm{L}$ galacturonic acid it also increased markedly from $1.875 \mathrm{mmol} / \mathrm{L}(-)$-epicatechin equivalent (Fig. 4f). For RG-IIs and AGP4 the absorption was stable.

The $\Delta K_{a v}$ values were very low to nil, even for AGP0, indicating that there was no selective precipitation of larger or smaller polysaccharides. The $\triangle \mathrm{DP} n$ was only markedly negative for AGP0, indicating that the more highly polymerized procyanidins were selectively precipitated by AGP0.

\section{Discussion}

Using isothermal titration calorimetry and absorbance at $650 \mathrm{~nm}$, rhamnogalacturonans and hairy regions were shown to interact with procyanidins whatever their degree of polymerization. Thermodynamic data measured by isothermal titration calorimetry enable to compare affinity between pectic fractions and procyanidins and to demonstrate that interactions could be driven by either enthalpy or entropy or both, indicating that procyanidins and pectic fractions can interact by different mechanisms, depending on the pectin side chains.

Interactions between hairy region fractions and procyanidins DP9 showed association constants of the order of $10^{3} \mathrm{M}^{-1}$, of the same order as with commercial pectins from apple (Watrelot et al., 2013), whereas interactions with procyanidins DP30 presented association constants ranging between $10^{2} \mathrm{M}^{-1}$ and $5 \times 10^{3} \mathrm{M}^{-1}$. Most of the associations between hairy regions and procyanidins DP9 were driven by entropy, which could indicate a contribution of hydrophobic interactions, while associations with procyanidins DP30 were driven by entropy (with RG, HR-H and MHR1) or by enthalpy for AHR, MHR2 and MHR3, i.e. those fractions might bind with procyanidins mainly through hydrogen bonds (Frazier et al., 2010; Poncet-Legrand et al., 2007). However, the pectic fractions conformation and structure could induce difference of binding systems through aggregation phenomenon for example. The differences in thermodynamic parameters observed between procyanidins were related to differences obtained by analysis of absorbance at $650 \mathrm{~nm}$ and analysis of supernatants after associations. With procyanidins DP30, aggregates appeared for some hairy region fractions, while with procyanidins DP9 formation of cloud or aggregate was very limited. The determination of $\Delta K_{a v}$ in this study showed that procyanidins, whatever their degree of polymerization, bind without selectivity with respect to size of hairy regions. Watrelot et al. (2013) showed that procyanidins DP30 interacted preferentially with smaller molecules of commercial apple pectins. The determination of $\triangle \mathrm{DP} n$ showed differences in hairy regions for binding to highly polymerized procyanidins DP30, unlike procyanidins DP9. The length of procyanidins DP30 facilitated aggregates formation (Carn et al., 2012). Procyanidins DP30 are a polymer more non-uniform than procyanidins DP9 (Le Bourvellec, Picot, \& Renard, 2006). This facilitated detection of the selectivity of hairy regions of pectins. 


\section{Journal homepage: www.elsevier.com/locate/carbpol}

HR-H was the simplest structure with rhamnogalacturonan and mono and dimeric side chains. Its association constant with procyanidin DP30 was high and the formation of precipitate showed a marked selectivity for highly polymerized procyanidins. The presence of few neutral sugar side chains on the rhamnogalacturonan backbone could allow a linear structure probably able to "stack" with procyanidins. Low association constants were observed for procyanidin DP30 interacting with arabinan-rich pectic fractions (AHR and MHR2). AHR was mainly composed of arabinan chains that have been suggested to adopt a 2-fold helical conformation (Janaswamy \& Chandrasekaran, 2005). Ha, Viëtor, Jardine, Apperley, and Jarvis (2005) demonstrated that arabinan chains were generally more mobile than galactan chains. The high mobility and the conformation of those chains could limit the association with procyanidins. For MHR2, it is concluded that the presence of galactan type II (1,3- and 1,6-linked galactans) with arabinans led to no modification of association with procyanidins (Goubet et al., 1995). Type II galactans possess lateral 1,3-linked $\beta$-D-galactan chains which adopt open helical structure and 1,6-linked $\beta$-Dgalactan side chains with a non-helical linear structure (Pérez, Mazeau, \& Hervé du Penhoat, 2000). This combination results in highly branched structures, which limits the association with procyanidins. The same phenomenon may occur with AGPs. MHR1, MHR3 and MHR4 fractions composed of type I galactan chains with 1,4 linkages, associated with procyanidins as efficiently as arabinan chains. However, due to the presence of xylogalacturonans, association constants cannot be defined. It can be suggested that xylogalacturonans are flexible enough to associate with procyanidins.

RGIIs do not bind procyanidins efficiently. The present results are not in agreement with aggregation phenomena observed by Riou, Vernhet, Doco, and Moutounet (2002) between dimeric RGII and tannins. Similarly, conflicting results were obtained for interaction between AGP0 and procyanidins DP30: we observed clear aggregation by absorption analysis, whereas this was not observed by previous dynamic light scattering investigation. It could be explained by the medium used by Riou, such as ionic strength, which induces a high self-aggregation of procyanidins and limits aggregation with AGP0 (Poncet-Legrand, Cartalade, Putaux, Cheynier, \& Vernhet, 2003).

\section{Conclusion}

Interactions between hairy regions of pectins and procyanidins were demonstrated and depend on composition and conformation of neutral sugar side chains of pectins and procyanidins. Capacity of association between procyanidins DP30 and hairy fractions of pectins could be ranked: arabinans $<$ arabinans + galactans II $<$ galactan $\quad$ I $<$ arabinans + galactan I + xylogalacturonans $<$ rhamnogalacturonan. Further investigations are still in progress with the same compounds by the dynamic light scattering (DLS) to measure the aggregates formation.

\section{Acknowledgements}

The authors thank Dr. Marie-Christine Ralet (INRA-UR1268 Biopolymères Interactions Assemblages, Nantes, France) for MHR from apple samples and their characterization, Dr. Henk Schols (WU Agrotechnology \& Food Sciences, Wageningen, Netherland) for MHR samples and their characterization, and Dr Claire Dufour (INRA-UMR408 Sécurité et Qualité des Produits d'Origine Végétale, Avignon, France) for RGIIs and AGPs. The research leading to these results received funding from the European Community's Seventh Framework Program (FP7/2007-2013) under the grant agreement No. FP7-222 654-DREAM.

\section{References}

Aura, A.-M., Mattila, I., Hyötyläinen, T., Gopalacharyulu, P., Cheynier, V., Souquet, J.-M., et al. (2012). Characterization of microbial metabolism of Syrah grape products in an in vitro colon model using targeted and non-targeted analytical approaches. European Journal of Nutrition, 52, 833-846.

Box, G. E. P., Hunter, W. G., \& Hunter, J. S. (1978). Statistics for experimenters. An introduction to designd 544 ata analysis and model building. John Wiley \& Sons: Wisconsin Univ., Madison, USA.

Caffall, K. H., \& Mohnen, D. (2009). The structure, function, and biosynthesis of plant cell wall pectic polysaccharides. Carbohydrate Research, 344, 1879-1900.

Carn, F., Guyot, S., Baron, A., Perez, J., Buhler, E., \& Zanchi, D. (2012). Structural properties of colloidal complexes between condensed tannins and polysaccharide hyaluronan. Biomacromolecules, 13, 751-759.

Cheynier, V., Sarni-Manchado, P., \& Quideau, S. (2012). Recent advances in polyphenol research. John Wiley \& Sons.

Clarke, A. E., Anderson, R. L., \& Stone, B. A. (1979). Form and function of arabinogalactans and arabinogalactan-proteins. Phytochemistry, 18, 521-540.

Coenen, G. J. (2007). Structural characterization of native pectins. Wageningen, Netherlands: Wageningen Universiteit (Wageningen University).

Coenen, G. J., Bakx, E. J., Verhoef, R. P., Schols, H. A., \& Voragen, A. G. J. (2007). Identification of the connecting linkage between homo- or xylogalacturonan and rhamnogalacturonan type I. Carbohydrate Polymers, 70, 224-235.

De Vries, J. A., Rombouts, F. M., Voragen, A. G. J., \& Pilnik, W. (1982). Enzymic degradation of apple pectins. Carbohydrate Polymers, 2, 25-33.

Frazier, R. A., Deaville, E. R., Green, R. J., Stringano, E., Willoughby, I., Plant, J., et al. (2010). Interactions of tea tannins and condensed tannins with proteins. Journal of Pharmaceutical and Biomedical Analysis, 51, 490-495.

Goubet, F., Bourlard, T., Girault, R., Alexandre, C., Vandevelde, M.-C., \& Morvan, C. (1995). Structural features of galactans from flax fibres. Carbohydrate Polymers, 27, 221-227.

Guyot, S., Doco, T., Souquet, J.-M., Moutounet, M., \& Drilleau, J.-F. (1997). Characterization of highly polymerized procyanidins in cider apple (Malus sylvestris var. kermerrien) skin and pulp. Phytochemistry, 44, 351-357.

Guyot, S., Marnet, N., Laraba, D., Sanoner, P., \& Drilleau, J.-F. (1998). Reversed-phase HPLC following thiolysis for quantitative estimation and characterization of the four main classes of phenolic compounds in different tissue zones of a french cider apple variety (Malus domestica Var. Kermerrien). Journal of Agricultural and Food Chemistry, 46, 1698-1705.

Guyot, S., Marnet, N., \& Drilleau, J.-F. (2001). Thiolysis-HPLC characterization of apple procyanidins covering a large range of polymerization states. Journal of Agricultural and Food Chemistry, 49, 14-20.

Ha, M.-A., Viëtor, R. J., Jardine, G. D., Apperley, D. C., \& Jarvis, M. C. (2005). Conformation and mobility of the arabinan and galactan side-chains of pectin. Phytochemistry, 66, 1817-1824.

Hemingway, R. W., \& Karchesy, J. J. (1989). Chemistry and significance of condensed tannins. Plenum Press.

Janaswamy, S., \& Chandrasekaran, R. (2005). Polysaccharide structures from powder diffraction data: Molecular models of arabinan. Carbohydrate Research, 340 , $835-839$.

Le Bourvellec, C., Bouchet, B., \& Renard, C. M. G. C. (2005). Non-covalent interaction between procyanidins and apple cell wall material. Part III: Study on model polysaccharides. Biochimica et Biophysica Acta (BBA) - General Subjects, 1725, 10-18.

Le Bourvellec, C., Picot, M., \& Renard, C. M. G. C. (2006). Size-exclusion chromatography of procyanidins: Comparison between apple and grape procyanidins and application to the characterization of fractions of high degrees of polymerization. Analytica Chimica Acta, 563, 33-43.

Le Bourvellec, Carine, Bouzerzour, K., Ginies, C., Regis, S., Plé, Y., et al. (2011). Phenolic and polysaccharidic composition of applesauce is close to that of apple flesh. Journal of Food Composition and Analysis, 24, 537-547.

Nakamura, A., Furuta, H., Maeda, H., Nagamatsu, Y., \& Yoshimoto, A. (2001). Analysis of structural components and molecular construction of soybean soluble polysaccharides by stepwise enzymatic degradation. Bioscience, Biotechnology, and Biochemistry, 65, 2249-2258.

Palafox-Carlos, H., Ayala-Zavala, J. F., \& González-Aguilar, G. A. (2011). The role of dietary fiber in the bioaccessibility and bioavailability of fruit and vegetable antioxidants. Journal of Food Science, 76, R6-R15.

Parada, J., \& Aguilera, J. (2007). Food microstructure affects the bioavailability of several nutrients. Journal of Food Science, 72, R21-R32.

Pellerin, P., Vidal, S., Williams, P., \& Brillouet, J.-M. (1995). Characterization of five type II arabinogalactan-protein fractions from red wine of increasing uronic acid content. Carbohydrate Research, 277, 135-143.

Pellerin, P., Doco, T., Vida, S., Williams, P., Brillouet, J.-M., \& O’Neill, M. A. (1996). Structural characterization of red wine rhamnogalacturonan II. Carbohydrate Research, 290, 183-197.

Pérez, S., Rodríguez-Carvajal, M. A., \& Doco, T. (2003). A complex plant cell wall polysaccharide: Rhamnogalacturonan II. A structure in quest of a function. Biochimie, 85, 109-121.

Pérez, S., Mazeau, K., \& Hervé du Penhoat, C. (2000). The three-dimensional structures of the pectic polysaccharides. Plant Physiology and Biochemistry, 38, 37-55.

Poncet-Legrand, C., Cartalade, D., Putaux, J.-L., Cheynier, V., \& Vernhet, A. (2003). Flavan-3-ol aggregation in model ethanolic solutions: Incidence of polyphenol structure, concentration, and ethanol content, and ionic strength. Langmuir, 19, 10563-10572. 
Poncet-Legrand, C., Gautier, C., Cheynier, V., \& Imberty, A. (2007). Interactions between flavan-3-ols and poly(l-proline) studied by isothermal titration calorimetry: Effect of the tannin structure. Journal of Agricultural and Food Chemistry, 55, 9235-9240.

Quideau, S., Deffieux, D., Douat-Casassus, C., \& Pouységu, L. (2011). Plant polyphenols: Chemical properties, biological activities, and synthesis. Angewandte Chemie International Edition, 50, 586-621.

Ralet, M.-C., Tranquet, O., Poulain, D., Moïse, A., \& Guillon, F. (2010). Monoclonal antibodies to rhamnogalacturonan I backbone. Planta, 231, 1373-1383.

Renard, C., Voragen, A., Thibault, J., \& Pilnik, W. (1991). Studies on apple protopectin. 5. Structural studies on enzymatically extracted pectins. Carbohydrate Polymers, $16,137-154$.

Renard, C. M. G. C., Crépeau, M.-J., \& Thibault, J.-F. (1995). Structure of the repeating units in the rhamnogalacturonic backbone of apple, beet and citrus pectins. Carbohydrate Research, 275, 155-165.

Renard, C. M. G. C., Lahaye, M., Mutter, M., Voragen, F. G. J., \& Thibault, J.-F. (1997). Isolation and structural characterisation of rhamnogalacturonan oligomers generated by controlled acid hydrolysis of sugar-beet pulp. Carbohydrate Research, 305, 271-280.

Renard, C. M. G. C., \& Jarvis, M. (1999). Acetylation and methylation of homogalacturonans 1: Optimisation of the reaction and characterisation of the products. Carbohydrate Polymers, 39, 201-207.

Renard, C. M. G. C., \& Ginies, C. (2009). Comparison of the cell wall composition for flesh and skin from five different plums. Food Chemistry, 114, 1042-1049.

Ridley, B. L., O’Neill, M. A., \& Mohnen, D. (2001). Pectins: Structure, biosynthesis, and oligogalacturonide-related signaling. Phytochemistry, 57, 929-967.

Riou, V., Vernhet, A., Doco, T., \& Moutounet, M. (2002). Aggregation of grape seed tannins in model wine-effect of wine polysaccharides. Food Hydrocolloids, 16, $17-23$.

Sanoner, P., Guyot, S., Marnet, N., Molle, D., \& Drilleau, J.-F. (1999). Polyphenol profiles of french cider apple varieties (Malus domestica sp.). Journal of Agricultural and Food Chemistry, 47, 4847-4853.
Saura-Calixto, F., Pérez-Jiménez, J., Touriño, S., Serrano, J., Fuguet, E., Torres, J. L., et al. (2010). Proanthocyanidin metabolites associated with dietary fibre from in vitro colonic fermentation and proanthocyanidin metabolites in human plasma. Molecular Nutrition \& Food Research, 54, 939-946.

Schols, H., Posthumus, M., \& Voragen, A. (1990). Hairy (ramified) regions of pectins. 1. Structural features of hairy regions of pectins isolated from apple juice produced by the liquefaction process. Carbohydrate Research, 206, 117-129.

Schols, H., \& Voragen, A. (1994). Hairy (ramified) regions of pectins. 4. Occurrence of pectic hairy regions in various plant-cell wall materials and their degradability by rhamnogalacturonase. Carbohydrate Research, 256, 83-95.

Schols, H. A., Bakx, E. J., Schipper, D., \& Voragen, A. G. J. (1995). A xylogalacturonan subunit present in the modified hairy regions of apple pectin. Carbohydrate Research, 279, 265-279.

Thibault, J., Renard, C., Axelos, M., Roger, P., \& Crepeau, M. (1993). Studies of the length of homogalacturonic regions in pectins by acid-hydrolysis. Carbohydrate Research, 238, 271-286.

Thomas, J. R., McNeil, M., Darvill, A. G., \& Albersheim, P. (1987). Structure of plant cell walls XIX. Isolation and characterization of wall polysaccharides from suspension-cultured douglas Fir cells. Plant Physiology, 83, 659-671.

Turnbull, W. B., \& Daranas, A. H. (2003). On the value of c: Can low affinity systems be studied by isothermal titration calorimetry? Journal of the American Chemical Society, 125, 14859-14866.

Voragen, A. G. J., Coenen, G.-J., Verhoef, R. P., \& Schols, H. A. (2009). Pectin, a versatile polysaccharide present in plant cell walls. Structural Chemistry, 20, 263-275.

Watrelot, A. A., Le Bourvellec, C., Imberty, A., \& Renard, C. M. G. C. (2013). Interactions between pectic compounds and procyanidins are influenced by methylation degree and chain length. Biomacromolecules, 14, 709-718.

Williamson, G., \& Clifford, M. N. (2010). Colonic metabolites of berry polyphenols: The missing link to biological activity? British Journal of Nutrition, 104, S48-S66.

Wojdyło, A., Oszmiański, J., \& Laskowski, P. (2008). Polyphenolic compounds and antioxidant activity of new and old apple varieties. Journal of Agricultural and Food Chemistry, 56, 6520-6530. 